\title{
PROTEINOGRAMA DO LIQÜIDO CEFALORRAQUIDIANO NA LEPRA
}

\author{
A. SPINA-França * \\ WILSON BROTTO **
}

O acometimento do sistema nervoso na lepra não costuma ser acompanhado de modificações do quadro liquórico. Ocasionalmente têm sido referidas alteraçōes do líqüido cefalorraquidiano (LCR), na maioria das vêzes em casos cuja evolução foge dos quadros clàssicamente determinados por essa doença ${ }^{1}$.

O presente estudo compreende a análise eletroforética das proteínas do LCR de pacientes portadores de lepra e tem como finalidade verificar se o proteinograma do LCR nessa afecção apresenta modificações próprias ou secundárias às alterações das frações protêicas do sôro sangüineo (sôro). Justificam a presente investigação o fato de terem sido evidenciadas, por meio do mesmo método, modificações do proteinograma do LCR em outras doenças cujo quadro liquórico clássico é também normal ${ }^{3}$ e o fato de ocorrerem alterações das proteinas do sôro na lepra ${ }^{2}$.

\section{MATERIAL E MÉTODOS}

Em 25 pacientes portadores de lepra (quadro 1), acompanhados no Departamento de Profilaxia da Lepra do Estado de São Paulo, foi estudado o comportamento das frações protêicas do LCR.

O tempo de evolução da doença não era maior do que 1 ano em 10 casos, variava entre 2 e 5 anos em 9 casos e era maior nos restantes. Em 18 casos a forma clínica da doença era inespecifica, em 4 era lepromatosa, em 3 tuberculóide. A reação de Mitsuda não foi feita em 1 caso, era negativa em 7 e positiva nos demais. O quadro neurológico era de tipo periférico em todos os pacientes, caracterizando-se por sintomatologia ramuscular e/ou troncular. Os dados referentes a cada caso estão reunidos no quadro 2 .

Em todos os casos foram estudadas as frações protêicas de uma amostra de LCR. O método empregado para o estudo foi o da eletroforese em papel, segundo a técnica descrita anteriormente ${ }^{4}$ e os resultados obtidos foram analisados mediante os padrões normais apresentados em outra ocasiãos.

Além do exame eletroforético das proteínas, foram feitos em cada amostra de LCR, o exame citológico, a determinação da taxa de proteínas totais, a reaçāo de Pandy e as reações de fixação do complemento para sifilis e para cisticercose.

Em 21 casos foi estudado também o perfil eletroforético das proteínas do sôro.

* Assistente extranumerário da Clínica Neurológica da Fac. Med; da Univ. São Paulo (Prof, A. Tolosa).

** Neurologista do Departamento de Profilaxia da Lepra do Estado de São Paulo. 


\begin{tabular}{|c|c|c|c|c|c|}
\hline & Caso & Nome & Sexo & Idade (anos) & Côr \\
\hline 1 & $\ldots \ldots$ & BGA & $F$ & 18 & Branca \\
\hline 2 & $\ldots \ldots \ldots \ldots \ldots$ & WBS & M & 55 & Branca \\
\hline 3 & $\ldots \ldots$ & IB & $\mathrm{M}$ & 28 & Branca \\
\hline 4 & $\ldots \ldots \ldots \ldots \ldots$ & $\mathrm{AC}$ & $\mathrm{M}$ & 45 & Branca \\
\hline 5 & & GFC & M & 41 & Branca \\
\hline 6 & $\ldots$ & $\mathrm{ND}$ & $\mathrm{M}$ & 43 & Branca \\
\hline 7 & $\ldots \ldots$ & $\mathrm{JD}$ & M & 29 & Branca \\
\hline 8 & . & IMS & $\mathrm{F}$ & 48 & Branca \\
\hline 9 & & $\mathrm{AF}$ & $\mathrm{F}$ & 37 & Branca \\
\hline 10 & $\cdots$ & MF & $\mathrm{F}$ & 30 & Branca \\
\hline 11 & $\ldots$ & ARG & $\mathrm{F}$ & 27 & Branca \\
\hline 12 & $\ldots \ldots \ldots$ & $A G$ & $\mathrm{M}$ & 41 & Branca \\
\hline 13 & $\ldots$ & LNM & $F$ & 54 & Branca \\
\hline 14 & $\ldots$ & JSM & $\mathrm{M}$ & 47 & Branca \\
\hline 15 & $\ldots$ & JN & M & 36 & Branca \\
\hline 16 & & LP & M & 35 & Branca \\
\hline 17 & . & ZPAP & $\mathbf{F}$ & 28 & Branca \\
\hline 18 & $\cdots$ & UMZ & $F$ & 35 & Branca \\
\hline 19 & $\ldots \ldots$ & LT & M & 22 & Branca \\
\hline 20 & .. & SBS & M & 51 & Preta \\
\hline 21 & & LS & M & 19 & Branca \\
\hline 22 & $\ldots$ & JRS & M & 43 & Branca \\
\hline 23 & $\ldots \ldots$ & JAR & M & 22 & Branca \\
\hline 24 & $\cdots$ & GLS & M & 30 & Branca \\
\hline 25 & $\ldots \ldots \ldots \ldots \ldots$ & ORS & $F$ & 50 & Branca \\
\hline
\end{tabular}

Quadro 1 - Identificação dos pacientes estudados.

\section{RESULTADOS}

Não foram encontradas alterações do LCR quanto ao número de células e ao teor protêico total; as reaçōes de Pandy e de fixação do complemento para sífilis e para cisticercose foram negativas.

Acham-se reunidos no quadro 3 os resultados do exame eletroforético das proteínas do LCR e no quadro 4 aquêles referentes às proteínas do sôro. As relaçōes entre o teor das fraçōes protêicas no LCR e no sôro são referidas no quadro 5. 


\begin{tabular}{|c|c|c|c|c|c|c|}
\hline & Caso & $\begin{array}{l}\text { Forma } \\
\text { clinica }\end{array}$ & Evolução & $\begin{array}{l}\text { Reação de } \\
\text { Mitsuda }\end{array}$ & $\begin{array}{c}\text { Quadro } \\
r\end{array}$ & $\begin{array}{c}\text { neurológico } \\
t\end{array}$ \\
\hline 1 & $\ldots \ldots \ldots \ldots \ldots$ & I & $6 \mathrm{a}$ & +++ & + & \\
\hline 2 & $\ldots \ldots \ldots \ldots \ldots$ & I & $1 \mathrm{a}$ & - & + & \\
\hline 3 & $\ldots \ldots \ldots \ldots \ldots$ & I & $1 \mathrm{a}$ & +++ & & + \\
\hline 4 & $\ldots \ldots \ldots \ldots \ldots$ & I & $1 \mathrm{a}$ & +++ & + & \\
\hline 5 & $\ldots \ldots \ldots \ldots \ldots$ & I & $2 a$ & +++ & & + \\
\hline 6 & $\ldots \ldots \ldots \ldots \ldots$ & $\mathrm{L}$ & $24 \mathrm{a}$ & - & & t+ \\
\hline 7 & $\ldots \ldots \ldots \ldots$ & I & $5 a$ & + & + & \\
\hline 8 & $\ldots \ldots \ldots \ldots \ldots$ & $\mathrm{L}$ & $22 \mathrm{a}$ & - & + & + \\
\hline 9 & $\ldots \ldots \ldots$ & I & $4 \mathrm{a}$ & +++ & & + \\
\hline 10 & $\ldots \ldots \ldots \ldots$ & $I$ & $4 a$ & $+t$ & + & \\
\hline 11 & $\ldots \ldots \ldots \ldots \ldots$ & I & $2 \mathrm{a}$ & +++ & + & \\
\hline 12 & $\ldots \ldots \ldots \ldots \ldots$ & I & $3 \mathrm{~m}$ & ++ & + & + \\
\hline 13 & $\ldots \ldots \ldots \ldots \ldots$ & I & $22 \mathrm{a}$ & - & & + \\
\hline 14 & $\ldots \ldots \ldots \ldots \ldots$ & I & $1 \mathrm{a}$ & ++ & & + \\
\hline 15 & $\ldots \ldots \ldots \ldots \ldots$ & I & $1 \mathrm{a}$ & $+t+$ & & + \\
\hline 16 & $\ldots \ldots \ldots \ldots \ldots$ & $\mathrm{L}$ & $1 \mathrm{a}$ & - & & + \\
\hline 17 & $\ldots \ldots \ldots \ldots \ldots$ & $\mathrm{T}$ & $4 \mathrm{a}$ & ++ & + & \\
\hline 18 & $\ldots \ldots \ldots \ldots \ldots$ & $\mathrm{T}$ & $2 \mathrm{a}$ & ++ & + & \\
\hline 19 & $\ldots \ldots \ldots \ldots \ldots$ & $\mathrm{I}$ & $1 \mathrm{a}$ & - & & + \\
\hline 20 & $\ldots \ldots \ldots \ldots \ldots$ & I & $6 \mathrm{~m}$ & +++ & + & \\
\hline 21 & $\ldots \ldots \ldots \ldots \ldots$ & I & $7 \mathrm{a}$ & & + & + \\
\hline 22 & $\ldots \ldots \ldots \ldots \ldots$ & I & $1 \mathrm{a}$ & +++ & + & \\
\hline 23 & $\ldots \ldots \ldots \ldots \ldots$ & I & 3 a & $t+$ & + & \\
\hline 24 & $\ldots \ldots \ldots \ldots \ldots$ & $T$ & $2 a$ & ++ & + & \\
\hline 25 & $\ldots \ldots \ldots \ldots \ldots$ & $\mathrm{L}$ & $12 \mathrm{a}$ & - & + & + \\
\hline
\end{tabular}

Quadro 2-Forma clínica da lepra (L lepromatosa; T, tuberculóide; I, inespecifica); tempo de evolução ( $\mathrm{m}$, meses; a, anos); resultado da reação de Mitsuda (一, negati$v a ;+$, fracamente positiva; ++ , positiva; +++ , fortemente positiva). Em todos os casos as manifestações neurológicas eram sugestivas de acometimento do sistema nervoso periférico, de tipo ramuscular $(\mathrm{r})$ e/ou de tipo troncular (t).

\section{COMENTARIOS}

1 - Proteinograma do LCR - Em 14 casos o proteinograma do LCR era normal; nos demais havia alterações do teor de uma ou mais frações protêicas. Em dois (casos 17 e 18) o perfil caracterizava-se por apresentar aumento do teor de $\beta$-globulina. Em três havia aumento discreto do teor de $\gamma$-globulinas (casos 6,8 e 25) e nos seis restantes havia aumento do teor de albumina (casos 2, 9, 10, 11, 19 e 22). 


\begin{tabular}{|c|c|c|c|c|c|c|}
\hline \multirow{2}{*}{ Caso } & \multirow{2}{*}{$\begin{array}{c}\text { Pré- } \\
\text { albumina }\end{array}$} & \multirow{2}{*}{ Albumina } & \multicolumn{4}{|c|}{$G l \circ b u l i n a s$} \\
\hline & & & $\alpha_{1}$ & $\alpha_{2}$ & $\beta$ & $\gamma$ \\
\hline 1 & 1,0 & 48,0 & 5,0 & 7,0 & 25,0 & 14,0 \\
\hline 2 & - & 61,4 & 3,2 & 4,3 & 24,5 & 6,6 \\
\hline 3 & - & 52,9 & 5,8 & 7,2 & 25,3 & 8,8 \\
\hline 4 & 6,0 & 48,5 & 6,5 & 8,0 & 23,0 & 8,0 \\
\hline 5 & 2,0 & 52,0 & 4,5 & 7,0 & 26,0 & 8,5 \\
\hline 6 & & 50,0 & 4,4 & 7,4 & 22,0 & 16,2 \\
\hline 7 & - & 60,0 & 3,5 & 5,5 & 18,0 & 13,0 \\
\hline 8 & & 45,4 & 4,2 & 10,4 & 23,2 & 16,8 \\
\hline 9 & & 63,5 & 6,5 & 7,5 & 15,2 & 7,3 \\
\hline 10 & 3,5 & 61,4 & 3,5 & 5,8 & 15,0 & 10,8 \\
\hline 11 & & 62,0 & 3,5 & 6,5 & 20,0 & 8,0 \\
\hline 12 & - & 51,3 & 5,4 & 8,0 & 22,8 & 12,5 \\
\hline 13 & 2,0 & 52,2 & 5,1 & 8,6 & 23,6 & 8,5 \\
\hline 14 & - & $\mathbf{5 1 , 2}$ & 7,0 & 8,3 & 22,5 & 11,0 \\
\hline 15 & - & 55,0 & 3,5 & 7,0 & 26,0 & 8,5 \\
\hline 16 & 1,5 & 58,2 & 3,6 & 5,5 & 19,0 & 12,2 \\
\hline 17 & - & 47,0 & 4,7 & 9,4 & 29,5 & 9,4 \\
\hline 18 & 4,1 & 40,0 & 3,8 & 6,8 & 33,0 & 12,3 \\
\hline 19 & - & 67,0 & 3,5 & 6,0 & 15,0 & 8,5 \\
\hline 20 & - & 48,9 & 5,5 & 7,1 & 26,7 & 11,8 \\
\hline 21 & 6,0 & 44,0 & 6,0 & 9,0 & 25,0 & 10,0 \\
\hline 22 & & 66,0 & 3,5 & 5,5 & 17,0 & 8,0 \\
\hline 23 & 2,4 & 57,9 & 3,5 & 5,5 & 22,7 & 8,0 \\
\hline 24 & - & 56,9 & 3,9 & 6,7 & 22,0 & 10,5 \\
\hline 25 & - & 55,3 & 3,9 & 5,8 & 19,8 & 15,2 \\
\hline
\end{tabular}

Quadro 3 - Teores relativos (\%) das frações protêicas do LCR, nos casos estudados. Legenda: para a pré-albumina, os teores menores que $1 \%$ são referidos como tracos (-).

Secundàriamente a essas alterações referidas ocorreram: diminuição dos teores das globulinas $\alpha$ e $\gamma$ (caso 2) e desta última (caso 9) entre os casos com aumento do teor albumínico; diminuição do teor de albumina em um dos pacientes com aumento do teor de $\beta$-globulina (caso 18). A fração pré-albumina estava ausente em 5 dos casos com outras alterações do proteinograma e estava presente nos 20 casos restantes. 


\begin{tabular}{|c|c|c|c|c|c|c|}
\hline \multirow{2}{*}{\multicolumn{2}{|c|}{ Caso }} & \multirow{2}{*}{ Albumina } & \multicolumn{4}{|c|}{ Globulinas } \\
\hline & & & $\alpha_{1}$ & $\alpha_{2}$ & $\beta$ & $\gamma$ \\
\hline 1 & $\ldots \ldots \ldots \ldots \ldots$ & 61,5 & 3,5 & 9,0 & 10,0 & 16,0 \\
\hline 2 & . & 58,0 & 3,0 & 8,0 & 12,0 & 19,0 \\
\hline 3 & & 48,0 & 4,5 & 7,0 & 12,0 & 28,5 \\
\hline 4 & & 49,5 & 5,0 & 12,3 & 14,4 & 18,0 \\
\hline 5 & . & 60,0 & 3,0 & 8,0 & 12,0 & 17,0 \\
\hline 6 & . & 39,2 & 4,8 & 14,5 & 11,0 & 30,5 \\
\hline 8 & $\cdots$ & 45,5 & 3,5 & 11,5 & 14,0 & 25,5 \\
\hline 9 & & 53,5 & 4,0 & 9,5 & 13,5 & 19,5 \\
\hline 10 & & 60,0 & 2,5 & 6,0 & 12,0 & 19,5 \\
\hline 11 & . & 54,0 & 3,0 & 9,5 & 15,5 & 18,0 \\
\hline 14 & . & 48,0 & 5,0 & 12,0 & 14,0 & 21,0 \\
\hline 15 & . & 58,5 & 4,0 & 9,5 & 9,5 & 18,5 \\
\hline 16 & . & 45,8 & 3,5 & 9,2 & 18,5 & 23,0 \\
\hline 17 & $\ldots$ & 54,0 & 5,0 & 11,0 & 12,2 & 17,8 \\
\hline 18 & $\cdots$ & 52,0 & 5,5 & 12,0 & 12,5 & 18,0 \\
\hline 19 & . & 66,0 & 3,5 & 6,5 & 9,0 & 15,0 \\
\hline 20 & . & 44,8 & 4,0 & 13,6 & 14,6 & 23,0 \\
\hline 21 & $\cdots$ & 45,0 & 4,5 & 9,5 & 13,0 & 28,0 \\
\hline 22 & $\ldots$ & 61,0 & 3,0 & 7,0 & 10,0 & 19,0 \\
\hline 23 & $\cdots$ & 57,0 & 5,0 & 9,0 & 9,5 & 19,5 \\
\hline 24 & $\ldots \ldots \ldots \ldots \ldots$ & 52,0 & 4,5 & 10,0 & 11,0 & 22,5 \\
\hline
\end{tabular}

Quadro 4 - Teores relativos (\%) das frações protêicas do sôro de 21 dos casos estudados.

Em 11 casos, portanto, foram encontradas alterações do proteinograma do LCR. Estas eram discretas na maioria das ocasiōes, estando relacionadas ao comportamento de uma ou outra das frações protêicas, não chegando a modificar o tipo fundamental do perfil protêico do LCR. O significado das alterações encontradas será discutido nos capítulos seguintes.

2 - Relação entre o proteinograma do $L C R$ e do sôro - A relação entre os teores das frações protêicas do LCR e do sôro, em condições normais, é representada por 1,0 para a albumina e para as $\alpha$-globulinas; por valôres entre 1,5 e 2,0 para a $\beta$-globulina (1,7 em média) e pela cifra de 0,5 para a $\gamma$-globulina 5 . Entre os 21 casos em que foram examinadas as proteinas do sôro, foram encontradas algumas alterações dessas relações. 


\begin{tabular}{|c|c|c|c|c|c|}
\hline & \multirow{2}{*}{ Caso } & \multirow{2}{*}{ Albumina } & \multicolumn{3}{|c|}{ Globulinas } \\
\hline & & & $\alpha$ & $\beta$ & $\gamma$ \\
\hline 1 & $\cdots \cdots \cdots$ & 0,8 & 1,0 & 2,5 & 0,9 \\
\hline 2 & $\cdots$ & 1,1 & 0,7 & 2,0 & 0,3 \\
\hline 3 & $\ldots \ldots \ldots \ldots \ldots$ & 1,1 & 1,1 & 2,1 & 0,3 \\
\hline 4 & $\ldots \ldots$ & 1,1 & 0,8 & 1.6 & 0,4 \\
\hline $\mathbf{5}$ & $\cdots \cdots$ & 0,9 & 1,0 & 2,2 & 0,5 \\
\hline 6 & $\ldots \ldots$ & 1,3 & 0,6 & 2,0 & 0,5 \\
\hline 8 & $\cdots$ & 1,0 & 1,0 & 1,7 & 0,7 \\
\hline 9 & $\cdots \cdots$ & 1,2 & 1,0 & 1,1 & 0,4 \\
\hline 10 & $\cdots \cdots \cdots$ & 1,1 & 1,1 & 1,2 & 0,6 \\
\hline 11 & $\ldots \ldots \ldots$ & 1,1 & 0,8 & 1,3 & 0,4 \\
\hline 14 & $\ldots \ldots \ldots \ldots$ & 1,1 & 0,9 & 1,6 & 0,5 \\
\hline 15 & $\ldots \ldots \ldots$ & 0,9 & 0,8 & 2,7 & 0,5 \\
\hline 16 & $\ldots \ldots \ldots \ldots \ldots \ldots$ & 1,2 & 0,7 & 1,0 & 0,5 \\
\hline 17 & $\cdots$ & 0,9 & 0,9 & 2,4 & 0,5 \\
\hline 18 & $\ldots \ldots \ldots$ & 0,8 & 0,6 & 2,6 & 0,7 \\
\hline 19 & $\cdots$ & 1,0 & 0,9 & 1,7 & 0,6 \\
\hline 20 & $\cdots \cdots \cdots$ & 1,1 & 0,7 & 1,8 & 0,5 \\
\hline 21 & $\cdots$ & 1,1 & 1,1 & 1,9 & 0,4 \\
\hline 22 & $\cdots \ldots \ldots$ & 1,1 & 0,9 & 1,7 & 0,4 \\
\hline 23 & $\ldots \ldots \ldots$ & 1,1 & 0,6 & 2,4 & 0,4 \\
\hline 24 & $\ldots \ldots \ldots \ldots \ldots$ & 1,1 & 0,7 & 2,0 & 0,5 \\
\hline
\end{tabular}

Quadro 5 - Relação entre os teores das fraçóes protêicas no LCR e no sôro.

Em 14 casos, a relação $\mathrm{LCR}$ /sôro do teor albuminico mostrava valôres maiores que a unidade, traduzindo tendência de ser maior no LCR que no sôro o teor dessa proteina. Essa observação corrobora o achado do perfil de tipo albumínico com a alteração mais freqüentemente encontrada no proteinograma do LCR.

Igualmente em 14 casos, a relação entre os teores de globulinas $\alpha$ se mostrou abaixo da unidade. Considerando que os teores dessas globulinas no LCR eram normais na maioria dos casos, a alteração do equilíbrio pode decorrer do fato de seus teores serem maiores no sôro. 
A relação entre os teores de $\beta$-globulina foi representada pela cifra de 1,7 em três casos. Em 12 os valôres eram maiores, $€ m$ 6, menores. Êsses dados mostram que tendem a se apresentar acima da média os valôres de tal reação.

Por sua vez, a relação entre os teores de $\gamma$-globulina mostrou oscilações não características; assim, era de 0,5 em 8 casos, maior que êste valor, em 5 e menor em 8. Na maioria das ocasiões, porém, as oscilações não eram grandes, tanto que entre 0,4 e 0,6 se encontram os valôres representativos de 16 dos 21 casos.

Em conjunto, essas observações mostram uma tendência para estabelecer-se um desequilíbrio entre as proteinas do LCR e do sôro na afecção, o qual é caracterizado, em relação ao LCR, por apresentar maior teor de albumina e de $\beta$-globulinas e menor teor de $\alpha$-globulinas.

3 - Proteinograma do LCR e aspectos clínicos - Foram analisadas as relações entre o proteinograma do LCR e o tempo de evolução da doença, sua forma clínica e o resultado da reação de Mitsuda.

a - Tempo de evolução - Em todos os casos com aumento do teor albumínico no LCR o tempo de evolução da doença era menor do que 5 anos, sendo que em três dêles, era de cêrca de um ano. Em vista disso, foi feita exploração da correlação entre o tempo de evolução e o teor albumínico, do LCR, que se mostrou insignificante $(r=0,19)$. O aumento de albumina, embora ocorra com maior intensidade nos periodos iniciais da doença, não está na dependência direta dêle, portanto. Para as demais frações não foi observado comportamento especial $\epsilon \mathrm{m}$ relação ao tempo de evolução da doença.

b - Forma clinica - Seis pacientes que apresentavam aumento do teor albuminico do LCR eram portadores de formas clínicas inespecíficas, enquanto que aquêles com aumento do teor de $\gamma$-globulina apresentavam lepra lepromatosa e os com aumento do teor de $\beta$-globulina, lepra tuberculóide. Em vista disso foram analisadas as médias dos teores das frações protêicas do LCR, grupando-se os casos segundo a forma clínica (quadro 6). A análise dêsse quadro permite verificar que o t€or albuminico era, em média, mais elevado no grupo de pacientes com a forma inespecífica da doença; o de $\gamma$-globulina no dos portadores de forma lepromatosa e o de $\beta$-globulina naqueles com lepra tuberculóide.

c - Reação de Mitsuda - Sendo o resultado desta reação um dos elementos primordiais na classificação das formas clínicas da lepra, é de supor que as relações observadas entre estas e o proteinograma do LCR encontrem confirmação no estudo comparativo entre as proteínas do LCR e o resultado dessa reação. O estudo das médias dos teores das frações protêicas do LCR, grupando-se os casos segundo o resultado da reação de Mitsuda (quadro 7), mostra que o teor de $\beta$-globulina tende a aumentar em relação à intensidade da positividade da reação de Mitsuda, enquanto 
que tende a diminuir o de $\gamma$-globulina. A correlação entre o teor de cada uma dessas globulinas e o resultado da reação de Mitsuda não foi significativa para a $\beta$-globulina $(r=0,24)$ e foi significativa para a $\gamma$-globulina $(r=-0,40 ; P \simeq 0,05)$.

\begin{tabular}{|c|c|c|c|c|c|c|}
\hline \multirow{2}{*}{ Forma clinica } & \multirow{2}{*}{$\begin{array}{c}N^{\circ} \text { de } \\
\text { casos }\end{array}$} & \multirow{2}{*}{$\begin{array}{c}\text { Albumi- } \\
n a\end{array}$} & \multicolumn{4}{|c|}{ Globulinas } \\
\hline & & & $\alpha_{1}$ & $\alpha_{2}$ & $\beta$ & $\gamma$ \\
\hline$I$ & 18 & 55,7 & 4,7 & 6,9 & 21,8 & 9,5 \\
\hline$I \ldots \ldots$. & 4 & 52,2 & 4,0 & 7,3 & 21,0 & 15,1 \\
\hline $\mathbf{T} \ldots \ldots \ldots \ldots \ldots \ldots \ldots$ & 3 & 48,0 & 4,1 & 7,6 & 28,2 & 10,7 \\
\hline
\end{tabular}

Quadro 6 - Teores médios (\%) das frações protêicas do LCR em relação à forma clínica da lepra: inespecifica (I), lepromatosa (L), tuberculóide (T).

\begin{tabular}{|c|c|c|c|c|c|c|}
\hline \multirow{2}{*}{ Reação de Mitsuda } & \multirow{2}{*}{$\begin{array}{c}N^{o} \text { de } \\
\text { casos }\end{array}$} & \multirow{2}{*}{$\begin{array}{c}\text { Albumi- } \\
n a\end{array}$} & \multicolumn{4}{|c|}{ Globulinas } \\
\hline & & & $\alpha_{1}$ & $\alpha_{2}$ & $\beta$ & $\gamma$ \\
\hline - & 7 & 55,6 & 4,0 & 6,9 & 21,0 & 12,0 \\
\hline$+a++$ & 6 & 54,6 & 3,9 & 6,4 & 22,3 & 11,2 \\
\hline+++ & 11 & 55,0 & 5,1 & 7,3 & 23,3 & 9,4 \\
\hline
\end{tabular}

Quadro 7 - Teores médios (\%) das frações protêicas do LCR em relação ao resultado da reação de Mitsuda.

Esses dados são paralelos ao que foi verificado em relação às formas clínicas, em especial no que se refere às globulinas $\beta$ e $\gamma$ e suas relações com as formas tuberculóide e lepromatosa, uma vez que o resultado da reação de Mitsuda constitui um dos elementos primordiais para a classificação.

A tendência a ser maior o teor de $\gamma$-globulinas no LCR nos casos com reação de Mitsuda negativa pode decorrer de um aumento da $\gamma$-globulinemia. A favor dessa hipótese alinham-se dados da literatura, citados anteriormente $^{2}$, segundo os quais os aumentos discretos do teor de $\gamma$-globulina não são característicos de processos inflamatórios sediados no sistema nervoso central ou em seus envoltórios mas resultam, em geral, de uma passagem de maior quantidade dessa globulina do sangue para o LCR. Na maioria das vêzes esta é secundária ao aumento do teor da $\gamma$-globulina no sangue; assim, continua a manter-se dentro da normalidade $(0,5)$ a relação entre os teores dessa fração no LCR e no sôro. Dos três casos em que havia aumento do teor da globulina no LCR, em dois foi feito exame das 
proteínas do sôro; a relação LCR/sôro do teor dessa globulina era normal em um (caso 6) e no outro não podia ser considerada patológica $(0,7)$, corroborando a asserção anterior. No mesmo sentido há outro elemento no material estudado, qual seja o fato de o teor médio dessa fração no sôro nos casos com positividade da reação de Mitsuda ser menor que naqueles nos quais era negativa $(19,6$ e $22,6 \%$, respectivamente).

Por outro lado, o fato de não se mostrar significativa a tendência a elevar-se o teor da $\beta$-globulinorraquia com a positividade da reação de Mitsuda sugere que o aumento seja devido à participação de outros fatôres, desencadeados paralelamente. Estes podem estar relacionados a alterações primárias ou secundárias do metabolismo neuronal, uma vez que o aumento dessa globulina no LCR tem sido relacionado diretamente a processos degenerativos do sistema nervoso central ${ }^{3}$.

O quadro 7 permite verificar que são muito próximos os teores médios de albumina para os três grupos de resultados da reação de Mitsuda. Esse fato vem mostrar que a provável relação entre o aumento do teor albumínico do LCR e a forma inespecífica da doença não se relaciona ao resultado da reação de Mitsuda. Outros fatôres podem ser responsáveis pela facilitação da barreira hêmato-liquórica em relação a essa proteína na lepra. Sua natureza não pôde ser explicada em relação aos dados analisados neste estudo.

\section{RESUMO E CONCLUSOES}

Foi estudado o proteinograma do LCR de 25 pacientes portadores de lepra. Os resultados são registrados e analisados em relação ao proteinograma do sôro, ao tempo de evolução da doença, à forma clínica de lepra e ao resultado da reação de Mitsuda.

O proteinograma do LCR estava alterado em 11 casos: em 6 havia aumento do teor de albumina, em 3 do teor de $\gamma$-globulina e em 2, do de $\beta$-globulina.

Foram encontradas alterações das relações normalmente existentes entre as frações protêicas do LCR e do sôro: havia tendência a ser maior que a normal a relação referente à albumina e $\beta$-globulinas; tendência contrária foi observada quanto às $\alpha$-globulinas.

$O$ aumento do teor de albumina no LCR foi observado em pacientes portadores de formas inespecíficas de lepra, com maior freqüência nos casos de curta evolução.

O aumento de $\beta$-globulina no LCR ocorreu em portadores de lepra tuberculóide. Havia correlação positiva entre o teor dessa fração e o grau de positividade da reação de Mitsuda. Tal correlação, porém, não se mostrou significativa.

O aumento da $\gamma$-globulinorraquia foi discreto em todos os casos, podendo ser secundário ao aumento do teor dessa fração no sôro e foi obser- 
vado em portadores de lepra lepromatosa. Havia correlação negativa entre o teor dessa globulina no LCR e o resultado da reação de Mitsuda; o valor dessa correlação mostrou-se estatìsticamente significativo.

\section{SUMMARY}

Cerebrospinal fluid proteins in leprosy.

The protein profile of the cerebrospinal fluid of 25 leprosy patients was studied. The results are compared to the serum protein profile, and correlated with the clinical progress of the disease, clinical form, and with the result of the Mitsuda reaction.

The protein profile wal altered in 11 cases with raise of the albumin fraction in 6 cases, of $\gamma$-globulin in three cases, and of $\beta$-globulin in two cases. The relationship between the proportions of the cerebrospinal fluid and serum proteins was found to be altered. The relationship was increased regarding to albumin and $\beta$-globulin, and reduced regarding to $\alpha$-globulin.

The increase in the albumin fraction of the cerebrospinal fluid was observed in patients with undifferentiated forms of leprosy, and with greater frequency in cases of short evolution.

The increase of the $\beta$-globulin fraction of the cerebrospinal fluid was observed in tuberculoid forms of the disease. Occurrence of an increase of this fraction and a positive Mitsuda test was observed, but statistical analysis of this showed no significant correlation.

The increase of the $\gamma$-globulin fraction of the cerebrospinal fluid was found in cases of lepromatous leprosy, and may be secondary to the increase of this fraction in the serum. Occurrence of an increase of this fraction and of a negative Mitsuda test was found, and the statistical analysis of this showed a significant correlation.

\section{REFERENCIAS}

1. JULIAO, O. F. - Manifestações nervosas da lepra. I Reunião Internacional de Neurologia Tropical, Buenos Aires, 1961. Em publicação. 2. RIBEIRO, L. P.; MITIDIERI, E.; AFFONSO, O. R. - Eletroforese em papel e métodos relacionados. Serviço Gráfico do I.B.G.E., Rio de Janeiro, 1958, pág. 87. 3. SPINA-FRANÇA, A. - Eletroforese em papel das proteinas do liquido cefalorraquidiano: principais resultados registrados na literatura. Arq. Neuro-Psiquiat., 16:223-235 (setembro) 1958. 4. SPINA-FRANÇA, A. - Eletroforese em papel das proteinas do líquido cefalorraquidiano: técnica. Arq. Neuro-Psiquiat., 16:236-242 (setembro) 1958. 5. SPINAFRANCA, A. - Eletroforese em papel das proteinas do líquido cefalorraquidiano: valores normais. Arq. Neuro-Psiquiat., 18:19-28 (março) 1960.

Clinica Neurológica - Faculdade de Medicina da USP - Caixa Postal 3461 São Paulo, SP - Brasil. 